\title{
The Principles of Humane Experimental Technique: Is It Relevant Today?
}

\author{
Alan M. Goldberg \\ CAAT, Bloomberg School of Public Health, Johns Hopkins University, Baltimore, MD, USA
}

\begin{abstract}
Summary
In the section on replacement in their 1959 book, The Principles of Humane Experimental Technique, Bill Russell and Rex Burch state: "As new fields of biology open in the future, it may become a matter of routine to apply the lessons of the past and turn as soon as possible to the techniques of replacement." They foresaw in vitro techniques, in their infancy at that time, as the science of the future. Today, in the US, the National Academy of Sciences publication of Toxicity Testing in the $21^{\text {st }}$ Century: A Vision and a Strategy proves their point. This pivotal publication recognizes that the future of toxicity testing lies in the use of human cells in culture and in methods that Bill Russell and Rex Burch could not have possibly conceived of in 1959 but which they identified generically as "the future."

To truly establish this $21^{\text {st }}$ Century approach will require very specific training in translational toxicology (the use of clinical observations to develop in vitro methods to understand pathways and systems biology), the development of transnational programs, and ways to evaluate the accuracy, validity and importance of new and/or traditional studies. These evaluations are known at evidence-based toxicology (EBT). Science is "the art of the question." The concepts identified above are the tools to answer these questions - and to lead us to the next round of questions. The principles that Bill Russell and Rex Burch developed during the 1954-59 writing of "The Book" may be more important today than ever before. They argued that the newest science, the most humane science is also the very best science. This hypothesis is being proven now, as each of us contributes to the world's body of knowledge.
\end{abstract}

\section{Introduction}

On this the $50^{\text {th }}$ anniversary of Bill Russell and Rex Burch's book, The Principles of Humane Experimental Technique (The Principles), I share the honor, with Michael Balls (FRAME), of presenting my thoughts on the relevance of this landmark publication to the conduct of science today. In brief, these Principles are more important than ever.

I had the pleasure of meeting Bill Russell and his wife Claire in their home in Reading, England in 1992. I met Rex Burch a few days later in Sheringham, England. With each of them, I shared stories, books, news clippings, and other publications illustrating the profound impact of their book, The Principles of Humane Experimental Technique, over the 30-plus years since its publication.

I visited Bill and Rex shortly after I was awarded the Russell and Burch Prize by the HSUS in 1991. At this point, Bill and Rex had not seen each other since the publication of their book. The two scientists went their separate ways, and neither had any idea of the impact of their work until Martin Stephens of the HSUS called them to get approval to use their names on the award.

Many of us subsequently had the pleasure of getting to know Bill, and those interactions have been amply recorded in two sets of publications - both of which are readily accessible in ATLA. The first is a series of obituaries of Bill, collected shortly after he died (Balls et al., 2006). The second is a collection of personal reflections given as part of FRAME's $40^{\text {th }}$ Anniversary celebration (2009, in press).

Rex Burch, on the other hand, is less well known. Unfortunately, few of us had the opportunity to spend much time with him. When I met Rex, he was the sole owner and sole employee of a small microbiology testing laboratory in the basement of the Town Hall of Sheringham, England. Since it was a one-person operation, Rex worked 7 days a week, 52 weeks a year. He was an exceedingly gracious host.

Rex's contribution to The Principles of Humane Experimental Technique lay primarily in conducting interviews and collecting data. We have little knowledge of his role in the planning of the book, organization of material, or actual writing of the manuscript. Perhaps, as the Russell archive is evaluated, we may learn more.

Michael and I each will share how we see the impact of The Principles. I have chosen to address the relevance of Bill and Rex's thinking and why their book is a monumental contribution that anticipates where we are today.

To answer the question, is The Principles relevant today, I will focus on four areas of activity essential to the future of in vitro sciences as they apply to Toxicology and Risk Assessment. These areas are: 1) training of scientists; 2) The NAS report: Toxicity Testing in the $21^{\text {st }}$ Century; 3 ) the Transatlantic Think Tank for Toxicology $\left(\mathrm{t}^{4}\right)$ : working together; and 4) humane sciences: the art of the question.

Plenary lecture held at the $7^{\text {th }}$ Worldcongress in Rome 2009 


\section{Training of scientists}

The principles of humane experimental technique reside in two concepts: humane science is the best science, and to practice humane science one must incorporate the 3Rs: reduction, replacement, and refinement. I list them alphabetically, rather than in the order suggested by The Principles, to emphasize that all Three Rs are critically important to good science (Goldberg, 2004).

Most scientists have not been taught the 3 Rs or the principles one must follow to practice humane science. For most, humane science is the untaught standard that the scientist strives for. Bill Russell and Rex Burch provided the tools; now we must make sure these tools are made available to all scientists. We also must make sure that we teach our students that failure to practice the most humane science can and will compromise the quality of their results.

I have the privilege of co-teaching a course titled "Animals in Research: Science, Policy and Law." It is offered twice per year - once as a classroom course and once as a distance education course with electronic communication and live talks. In the past two years, about 50 students have taken the course. These students get it. Their questions, their discussions, and their defense of proper use of animals in research all tell me that animal research will only be accepted if humane science is practiced.

\section{Toxicity Testing in the $21^{\text {st }}$ Century: a Vision and a Strategy}

The US Environmental Protection Agency (EPA) contracted with the National Academy of Sciences (NAS) to address the question of what toxicology testing will look like in the $21^{\text {st }}$ century. The resultant final publication is remarkable (Committee on Toxicity Testing and Assessment of Environmental Agents, NAS, 2007). It truly looked into the future and suggested a clear and uncompromising path to fulfill the vision. The publication has been widely recognized prior to this meeting, and at this meeting several awards have been presented to the Academy and the Authors.

The report has four basic conclusions:

- Animal research is expensive

- Animal research is not always predictive of human consequences

- The future of toxicology lies in the use of human cell systems in culture

- To understand toxicity we must understand pathways (mechanisms) and systems biology

These are the same concepts that the Johns Hopkins Center for Alternatives to Animal Testing (CAAT) has focused on since our founding in 1981. From the outset, we funded research on mechanisms and human cells in culture. I wish I could take credit for all of it, but the Advisory Board of CAAT was more than a co-equal partner.

Two additional aspects of a $21^{\text {st }}$ Century toxicology warrant consideration here: translational toxicology and evidencedbased toxicology (EBT). The NAS report does not directly ad- dress these topics, but both are important as we complete the paradigm shift in toxicology.

Translational toxicology involves, first, using observations in clinical or toxicological events and designing in vitro and/ or mechanistic approaches to understand the observation; then, using the newly developed in vitro methods to evaluate different chemicals with these methods; and finally, developing approaches to predict in vivo consequences from in vitro data. Clear examples of this approach have been developing over the last few years (Sawada et al., 2005).

Evidence-based toxicology is an extension of evidencedbased medicine. It is a structured approach to literature evaluation. Evidenced-based approaches serve to eliminate studies that do not meet the criteria for inclusion in summary evaluations and to strengthen those studies that do meet the criteria. Studies or methods that do not have scientific validity or scientific rigor are eliminated. In clinical medicine this allows one to identify "best" treatment options. In toxicology it will allow better risk assessment and management of chemicals. One example of an evidenced based approach is the Cochrane Collaboration (The Cochrane Collaboration, founded 1993). The Cochrane Collaboration provides a wonderful example of the depth of information that can be achieved with evidence-based approaches.

The Principles anticipated what has become the toxicology of the $21^{\text {st }}$ century. It states, "As new fields of biology open in the future, it may become a matter of routine to apply the lessons of the past and turn as soon as possible to the techniques of replacement" (p.104). Bill and Rex recognized that in vitro techniques, in their infancy at that time, would become the science of the future.

\section{$4 t^{4}$ - Transatlantic Think Tank for Toxicology}

In the early 90s, when I was a Trustee of the DoerenkampZbinden Foundation, I pushed the foundation to establish endowed chairs in in vitro toxicology to guarantee the future of the field and to enhance the impact of the foundation's work. The first chair was awarded to Marcel Leist at the University of Konstanz, Germany. My term as a Trustee with the Foundation was completed, but the idea was in place and well supported. The next chair was established at the University of Utrecht in the person of Bas Blaauboer, who was followed most recently by Thomas Hartung at the Johns Hopkins University.

Prior to his arrival at Hopkins, Thomas had already established the Transatlantic Think Tank for Toxicology $\left(\mathrm{t}^{4}\right)$ to serve as an incubator for new ideas and to provide a forum where concepts can be discussed at an international level. Its agenda is to examine ideas and concepts in light of changing science and regulation. Thomas asked me to be a principal member of $\mathrm{t}^{4}$, along with the Doerenkamp-Zbinden Professors. The initial activities were defined at the time of the 2009 SOT meeting in Baltimore, as Thomas arrived and was installed officially as the Doerenkamp-Zbinden Professor and Endowed Chair for Evidence-based Toxicology. 
The first publication identified as coming from the $\mathrm{t}^{4}$, "Reevaluation of animal numbers and cost for in vivo tests to accomplish REACH legislation requirements for chemicals - a report by the Transatlantic Think Tank for Toxicology $\left(t^{4}\right)$," written by Constanza Rovida and Thomas Hartung, was published in the 3/09 issue of ALTEX. A two-page version of the paper appeared in Nature (27 August 2009). This paper cogently argues that, since the initial evaluation of cost and numbers of animals required to meet the requirements of $\mathrm{REACH}$, many intervening circumstances have resulted in significantly higher figures on both counts. Rovida and Hartung demonstrate that the actual costs of meeting the $\mathrm{REACH}$ requirements will require some 54 million animals and $\$ 9.5$ billion. Both figures are unacceptable and undoable. This makes it all the more imperative that we fulfill the NAS Vision and Strategy.

The $\mathrm{t}^{4}$ also will participate in the implementation of the NAS report, Toxicity Testing in the $21^{\text {st }}$ Century. These related but separate activities form the basis of the paradigm shift in toxicology. In vitro toxicology has been established on a solid foundation of activities that span the globe. The $\mathrm{t}^{4}$ is a major building block of this foundation.

\section{Humane science: the art of the question}

As we move from animal studies to in vitro studies, the goal of humaneness is generally achieved. As Michael Balls points out in his companion piece, The Principles require that refinement and reduction be used together.

Science can be defined as the art of the question. The better the question, the better the science. Humane science - the $3 \mathrm{Rs}$ in practice - requires a very different set of questions. In the US, the responsibility for posing the appropriate questions is shared between the investigator and the Institutional Animal Care and Use Committee (IACUC). The investigator has the responsibility to ask whether the experiment will answer the question asked, whether the species selected is the best choice, and whether the experimental design, including the number of animals, is planned so as to maximize the benefits of the question. The IACUC, by law, does not look at the science. Its role is to examine whether the above identified parameters are fulfilled. It asks such questions as: Are methods available that would make these experiments more humane? Are non-invasive methods available? Are they being used? Have humane endpoints been considered? Is this the best approach to answer the question being addressed?
In The Principles, Bill and Rex hypothesize that humane science is the best science. Over the last 50 years, the scientific community has proven their hypotheses to be true. The title of this talk: The Principles of Humane Experimental Technique: Is It Relevant Today?

The answer: A resounding yes.

\section{References}

Balls, M., Paskal, C., Kirkwood, J. et al. (2006). An appreciation of the life of Professor William Russell. ATLA 34, 469-487.

Committee on Toxicity Testing and Assessment of Environmental Agents, Board on Environmental Studies and Toxicology, Institute for Laboratory Animal Research, National Research Council of the National Academies (2007). Toxicity testing in the 21 st century: $a$ vision and a strategy. Washington, D.C.: The National Academies Press.

Goldberg, A. M. (2004). The sixth annual FRAME lecture on animals and alternatives: societal expectations and scientific need. ATLA 32, 545.

Hartung, T. and Rovida, C. (2009). Chemical regulators have overreached. Nature 460, 1080-1081.

Personal reflections on Bill Russell. FRAME's 40th anniversary celebration (2009), in press.

Rovida, C. and Hartung, T. (2009). Re-evaluation of animal numbers and costs for in vivo tests to accomplish REACH legislation requirements for chemicals. ALTEX 26(3), 187-208.

Russell, W. M. S. and Burch, R. L. (1959). The Principles of Humane Experimental Technique. London: Methuen \& Co. Special edition published by Universities Federation for Animal Welfare (UFAW), 1992.

Sawada, H., Takami, K. and Asahi, S. (2005). A toxicogenomic approach to drug-induced phospholipidosis: Analysis of its induction mechanism and establishment of a novel in vitro screening system. Toxicol. Sci. 83, 282-292.

The Cochrane Collaboration: The reliable source of evidence in health care. See: http://www.cochrane.org.

\section{Correspondence to}

Alan M Goldberg, Ph.D.

Bloomberg School of Public Health

Johns Hopkins University

615 N Wolfe Street, Room7032

Baltimore, MD 21205

USA

e-mail: agoldberg@jhsph.edu 